\title{
Institutional Approach to Managing Business Concentration at the Industrial and Regional Level
}

\section{Gallyamova D.Kh.}

Kazan Federal University, Institute of Management, Economics and Finance, Kazan, 420008, Russia

Malganova I.G.

Kazan Federal University, Institute of Management, Economics and Finance, Kazan, 420008, Russia

Safiullin L.N.

Kazan Federal University, Institute of Language, 420008, Kazan, Russia

Antonova N.V.

Kazan Federal University, Institute of Management, Economics and Finance, Kazan, 420008, Russia

\section{Doi:10.5901/mjss.2014.v5n28p18}

\section{Abstract}

This article presents an analysis of business concentration processes and their connection with the evolutionary approach in modern economy, which implies a need for using various approaches to managing and measuring enlargement processes at all economic levels. It contains analyses of business concentration efficiency, especially at the industrial level; management of changes in interaction between economic entities of particular sectors caused by globalization processes in the economy. The article evaluates the need for a linkage between corporate structures, industries and regions, and its impact on economic phenomena.

Keywords: business concentration, business centralization, institutional approach, institute, spillover costs.

\section{Introduction}

Institutional approach as a trend in the research on economic phenomena and processes is based on the notion that technology is the key factor in economic efficiency. The vector of technological development depends on how various business entities, including the state, achieve their goals and interests. This creates the following market policy dilemma: one should understand the market system as a micro- and macroeconomic management system, which could be improved by integrating wider-base management (including business concentration), otherwise, a more efficient antimonopoly policy is needed to repair a pure market-based system. Anyway development of a certain institutional system to help resolve most efficiently the market regulation task is absolutely essential. In the former case emergence and evolution of an institutional structure is related to concentration processes, in the latter case it regards active state supervision in regulating the market. Despite different nature of institutions which are to appear in both cases, their creation is inevitable.

Institutions in any economic system are basically aimed to change the structure of human and institutional interaction grounds. Institutional evolution determines development pathway of the society and its separate subsystems in time, which can be employed to study regularities and manage economic development of the industrial complex. In essence, business concentration analyzed here, is one of institutional forms of sectoral development, aimed at encouraging companies to concentrate their resources in order to reduce transaction costs in the context of economic globalization. Or, to put it another way, the drive to rationalize the processes implies focus on conservation of scarce resources, and acknowledgement of limitations of cognition encourages us to investigate economic institutions. Also important is the fact that creation of a positive background induces only a short-term economic advance. For example, the crisis of 1998 on the world oil market weakened the power of home market merchants importing certain products, but in the course of time they regained their positions [1]. Hence, economics needs fully functional market institutions, since 
only they can make it possible to develop high value-added economic sectors, provide long-term economic growth, secure investments, and develop trade. Numerous research studies, which prioritize further development of market institutions for successful economic reforms, support the point.

Hence, acknowledgement of the possibility to implement institutional technologies in managing innovative structural changes provide thematic justification for investigating basic categories, as well as institutional development pathways and techniques of institutional changes in this study. Applying institutional approach to managing economic sector development demonstrates the relevance of a more profound study of both market and non-market forms of organization, which undoubtedly include business concentration. In the field of petrochemical industry business concentration makes it possible to employ our limited cognitive abilities to the benefit of meso-system (innovation resources), using two major methods [4]. First, in the course of decision making process, which requires development of tooling to evaluate integration efficiency; second, with the help of government agencies or sectoral development institutions.

\section{Methods}

The use of institutional approach to assess business concentration efficiency requires considering implications and product, resulting from cooperation with the sector institutions. To analyze the consequent effect of institutional techniques on petrochemical industries we need to divide them into two groups: coordinate and distributive. Such a division is mainly determined by the purpose of regulatory institutions. They provide balance in competing interests. The former case refers to the degree of eligibility of factual profits and expenditures. As for the second aspect, it is especially relevant while assessing the reduction of transaction costs for certain sector groups (monopolies, opponent sector) since it is related to specific distribution of additional added cost and investments, as well as expenses involved in following the rules while managing sectoral subsystems.

A distinctive feature of non market institutions created at the sector level of business concentration process, which should be taken into consideration while conducting an extensive analysis of sector performance, consists in producing specific goods, i.e. functional products, which form, support and expand functional abilities and powers of economic systems, used in market-based economy and increasing its productivity. Examples of such functional products include industrial regions, specific economic areas and other institutional formations whose creation is weakly initiated within the framework of market economy.

In the context of economic globalization non market institutions can provide a more effective solution to the problem of sector development and cut social expenditure. Production and consumption of these functional products are no less different from production and consumption of ordinary market goods and services, than production and consumption of intellectual products. But unlike the letter, production and consumption of functional products is not driven by market mechanisms, but specific institutional ones, which require a serious study with due regard for distinctive features of petrochemical sector.

\section{Results}

From the perspective of business concentration analysis in the context of economic globalization it is necessary to match reasons of changes and the preconditions for transforming institutions, which have been classified in the works written by Russian and foreign economists. From the whole list we have chosen the following factors which are social and economic by nature:

- Macroeconomic changes, caused either by domestic macroeconomic management (Polterovich, Nort) or external factors (globalization) [3];

- Random creation of institutions and their subsequent natural selection according to efficiency criterion (Alchen) [6];

- Technological process (Shumpeter) defining the relevance of cooperation in sector industries and organizing innovation networks [5];

- Goal-oriented innovative activities of mezo- and macroeconomic nature, and institutional designing (construction) associated with them, i.e. conscious goal-oriented activity, aimed to create institutions (Shastitko, Tambovtsev) [7];

- "Transplantation" (borrowing) of institutions, i.e. intentional measure of relocating institutions from one subnational entity or state to another (Polterovich); 
- Institutional momentum, motion of an institutional organization along an exogenous historical trajectory (Nort) [9];

- "Friction" which implies interaction between institutions (Hodgson), for instance, international and domestic institutions amid global competition [10];

Demand for progressive structural changes in the economic sector via business concentration implies real definition of the corresponding institutional pathways. Institutional trajectories describe changes in any given totality of institutions in time. At each particular stage the institutional structure as a totality of institutions can include:

- Elements, which are either spontaneous or affected by previous institutional formations;

- Elements of the new institutional environment, either intrinsic or borrowed [2].

Hence, while implementing institutional technologies to provide structural changes it is important to consider the complexity of institutional systems which consists in two factors: institutions being interconnected and inhomogeneous [8]. Therefore before you engage in any serious undertakings you should give consideration to the institutional complementarity principle, which states that institutions complement each other and the desirable economic effect can be achieved only through interconnected institutional changes. The extent of institutional complementarity determines the performance of the whole group and can act as a separate subject matter.

There is no unified approach to forming trajectories for institutional changes. For example, there are evolutional rationalism (spontaneous development) and political judicial constructivism (swift drastic changes) on the one hand, and institutional growth theory on the other. There are two possible ways to set these two schemes of institutional changes aside. The first one consists in improving the existing institutional system. The second implies creation of new institutions.

Institutional development trajectories are also known as local search (natural process of institutional formation and development) and deliberate institutional construction, which is typical for the state authorities. In the first instance, it is the small innovation institutions which are developed, long-range goals playing a minor role. What is more, being deliberate at the micro level, after aggregating to meso- and macro-level, institutional changes become increasingly spontaneous. The first development trajectory has the disadvantage, however, of possible emergence of traps (inefficient institutional scheme), which can be based even upon positive changes (adverse selection scheme).

As for the second tendency (type of trajectory), there exist two essentially different ways to generate intended and intermediate institutions: construction, i.e. creation of fundamentally new institutions, and transplantation, i.e. borrowing institutions from other, usually advanced, systems [11].

Finally, an important category in implementing plant concentration techniques can be considered that of institutional experimenting as a key method to tackle institutional innovations. Given method can be considered applicable to both approaches to estimating institutional development trajectory at the sectoral level, since its implementation leads to reduction of possible expenditures.

Returning again to the problem of assessing progressivity of changes resulting from business concentration, one should note the need for changing the drift in accordance with the previously chosen institutional development pathway. In other words, when discussing the assessment of business concentration efficiency at the sectoral level, we need to consider the fact that business concentration implies modifications in the institutional structure of economic sectors. Therefore, the relation between plant concentration at the corporate level, plant concentration at the sectoral level and changes in institutional structure of the sector becomes evident.

\section{Conclusion}

The prospective trajectory of institutional development is a development pathway created at the sectoral level in conformity with resource, technological and institutional restrictions and considering integrated mechanisms to foster the predesigned institutional changes and prevent any sort of disorder and institutional traps. Regarding the business concentration processes at the sectoral level it would be totally wrong to consider the sector within the national economy framework in view of substantial inhomogenuity of the latter. This presupposes a specific choice of sectoral development entities with regard to the specific nature of the region.

Therefore, in the context of institutional approach, the cooperative networks setting partnership between corporate structures, sector and region become visible. Institutional approach to plant concentration management implies need for a tight web of connections between these tree entities to form a coherent whole. 


\section{References}

Galliamova DH Features of the process of centralization of production in a globalizing world economy. Development background, problems and perspektivy.-K. Univ Kazansk.un Press, 2007. 228 pp.

Kleiner GB Features of the formation and evolution of the socio-economic institutions in Russia // Preprint., 2001. 126 p.

North D. Institutional Economics. Institutions, Institutional Change and Economic Research Center // Source "SocioEgo" http://www.socioego.ru

Polterovich V., Popov Evolutionary Theory of Economic politiki.Ch.1 // Problems of Economics. 2006.№7. S.4-23, №8. S.46-65.

J. Schumpeter, Capitalism, Socialism and Democracy. M., 1995.

Alchlan A. Uncertainty, Evaluation and Economic Theory // Journal of Political Economy, June 1950, p.211-221.

Hayek F.A. Studies in Philosophy, Politics and Economics. London: Routledge \& Kegan Paul, 1967.

M. Afanasyev, AL Myasnikov global competition and clustering economy // Problems of Economics. 2005. №4. S. 75-86.

Galliamova DH Features of the process of centralization of production in a globalizing world economy. Development background, problems and perspektivy.-K. Univ Kazansk.un Press, 2007. 228 pp.

Nelson, RR, Winter SJ. Evolutionary Theory of Economic izmeneniy.- M .: Case, 2002.- 536 p.

O. Williamson Behavioral background of modern economic analysis // Oliver E. Williamson. Behavioral Assumptions. In: O.E. Williamson. The Economic Institutions of Capitalism. Firms, Markets, Relational Contracting. N.Y .: The Free Press, 1985, p.44 52.

Razumovskaya, E.M.,Mishakin, T.S., Popov, M.L., Kucevol, N.G. Medical services during the XXVII world summer universiade 2013 in Kazan. Mediterranean Journal of Social Sciences vol. 5 (18 SPEC. ISSUE), pp. 17-20

Arustamyan, G.,Yegorov, E., Lipsky, S.,Razumovskaya, E.,Gimranova, L. Clinical and economic analysis and its role in healthcare quality management. World Applied Sciences Journal vol. 27 (3), pp. 318-323.

Shaidullin R.N., Safiullin L.N., Gafurov I.R., Safiullin N.Z.. Blended learning: leading modern educational technologies. Procedia - Social and Behavioral Sciences. Vol. 131, pp. 105-110. // 3rd World conference on educational technology researches Turkey 0709.11.2013. 